\title{
Epidermoid Cyst of the Testis 5-Year Follow-Up Results in Adults
}

\author{
Caner Ediz ${ }^{1}$, Aysenur Ihvan'2, Bulent Kati ${ }^{3}$, Serkan Akan¹, Omer Yilmaz ${ }^{1}$ \\ ${ }^{1}$ Department of Urology, Health Sciences University Sultan Abdulhamid Han Education and Research Hospital, Istanbul, Turkey \\ ${ }^{2}$ Department of Pathology, Health Sciences University Umraniye Education and Research Hospital, Istanbul, Turkey \\ ${ }^{3}$ Department of Urology, Harran University Research Hospital, Sanliurfa, Turkey \\ Email: ^drcanerediz@gmail.com
}

How to cite this paper: Ediz, C., Ihvan, A., Kati, B., Akan, S. and Yilmaz, O. (2019) Epidermoid Cyst of the Testis 5-Year Follow-Up Results in Adults. Open Journal of Urology, 9, 69-76.

https://doi.org/10.4236/oju.2019.94008

Received: February 11, 2019

Accepted: April 23, 2019

Published: April 26, 2019

Copyright (c) 2019 by author(s) and Scientific Research Publishing Inc. This work is licensed under the Creative Commons Attribution International License (CC BY 4.0).

http://creativecommons.org/licenses/by/4.0/ cc) (i) Open Access

\begin{abstract}
Background: In this study, we aimed to share our experiences in patients with epidermoid cyst of the testis. We report the demographic and clinical characteristics and the long term results in patients with epidermoid cysts. Materials and Methods: Thirteen patients with epidermoid cyst of the testis treated between June 2000 and January 2018 were retrospectively evaluated. Ten patients with available data were included in the study. Patients' age, scrotal localization of symptoms, physical examination findings, serum tumor marker levels, pathology results and follow-up periods were recorded. Results: The current cohort consisted of 10 patients. The mean age at diagnosis was 29.7 years (range, 20 to 53 years). Eighty percent of the lesions were localized to the left hemiscrotum and $20 \%$ to the right hemiscrotum. One patient had a history of unilateral undescended testis. Serum tumor markers were normal in all patients. The mean scrotal mass lesion volume at diagnosis was $28 \mathrm{~mm}^{3}$ (range, 13 to $51 \mathrm{~mm}^{3}$ ). The mean follow-up period was 66.9 months (range, 12 to 216 months). Conclusions: Epidermoid cyst of the testis should be kept in mind, particularly in patients with lesions negative for tumor markers and radiological findings typical of epidermoid cysts. Annual follow-up is not required.
\end{abstract}

\section{Keywords}

Epidermoid Cyst, Testis, Germ Cell Tumor

\section{Introduction}

Epidermoid cyst of the testis is a benign simple epithelial tumor and an uncommon lesion that accounts for about $1 \%$ of all testicular masses [1] [2]. Dockerty and Priestly first described testicular epidermoid cyst in 1942 [3]. The etiology is 
not exactly known and the most widely accepted theories include monodermal development of a teratomaor squamous metaplasia of surface mesothelium [4] [5]. It is more commonly unilateral and has a slightly higher prevalence in the right testis. In testicular epidermoid cysts, inguinal orchiectomy is sufficient treatment, whereas in childhood, partial orchiectomy or enucleation is performed. We report demographic and clinical characteristics and the long-term outcomes of patients with epidermoid cyst of the testis.

\section{Materials and Methods}

\subsection{Study Population}

Thirteen patients with epidermoid cyst of the testis treated in Sultan Abdulhamid Han Training and Research Hospital, Umraniye Training and Research Hospital and Harran University Research Hospital between June 2008 and June 2018 were included in the study. The data were collected retrospectively. No ethical committee approval was required, owing to the retrospective nature of our study.

The current cohort included 10 patients with available data. Patients over 18 years of age with epidermoid cysts and available data were included in the study. The exclusion criteria included age under 18 years, suspected malignant pathology and unavailability of data.

The patients' medical records were reviewed. Patients' data including age, initial complaints (such as scrotal pain, swelling, mass or infertility), location of tumor (the right or left testis), smoking habit, history of undescended testis, family history, preoperative lactate dehydrogenase (LDH), alpha-fetoprotein (AFP) and $\beta$-human chorionic gonadotrophin ( $\beta$-HCG) levels, diagnostic imaging findings, pathology results and follow-up time were evaluated.

\subsection{Clinical Examination and Biochemical Measurements}

For all scrotal masses; each testicle was examined with both hands. All patients were routinely evaluated with scrotal ultrasonography. Contrast-enhanced magnetic resonance imaging was performed if required. Testicular mass volume was measured using the following formula: length $(\mathrm{L}) \times$ width $(\mathrm{W}) \times$ height $(\mathrm{H}) \times$ 0.52 [6]. Imaging methods and results were evaluated by specialized uroradiologists. Routine inguinal approach and orchiectomy were performed for all scrotal masses in our clinics. Pathologic specimens were reviewed by three genitourinary pathologists. Annual follow-up was recommended for all patients.

\subsection{Histopathological Examination}

All testicular materials were macroscopically sampled and the sections of each case were examined by uropathologists. The tissue samples were processed in a tissue processor overnight. The tissues were embedded in paraffin blocks and multiple recuts were made from the blocks. Then, the staining process was performed. The surgical specimens of testicular tissues were examined histologically 
with routine hematoxylin-eosin $(\mathrm{H} \& \mathrm{E})$ staining.

\subsection{Study Design}

Demographic characteristics of the patients were recorded and possible etiologic factors were identified. Radiological and pathological differential diagnoses were evaluated. The reasons for possible recurrences or relapses that may occur in the follow-up period were planned to be investigated.

\subsection{Statistical Analysis}

In the analysis of the data, the descriptive statistics were presented as means (minimum-maximum) for continuous variables. Discontinuous variables were defined as present or absent.

\section{Results}

For the 10 patients included in the analyses, the mean age was 29.7 years (range, 20 to 53 years). In 8 of 10 patients who admitted with testicular mass, lesions were located on the left side of the scrotum, while they were located on the right side in 2 patients. One patient presented with scrotal pain (10\%). Three patients had scrotal swelling (30\%). Three patients had both scrotal pain and swelling (30\%). Three patients with a testicular mass presented with a painless lump (30\%). Of the patients, $70 \%$ were smokers or tobacco users. However, no possible etiologic factors were found. One patient (10\%) had been followed up with the diagnosis of undescended testis in childhood but no surgical treatment was performed. None of the patients had a family history of epidermoid cyst. In all patients, the preoperative mean $\beta$-hCG, AFP and LDHisoenzyme levels were normal and $1.16 \mathrm{mIU} / \mathrm{ml}, 1.24 \mathrm{ng} / \mathrm{ml}$, and $265.44 \mathrm{U} / \mathrm{l}$, respectively. All patients underwent inguinal orchiectomy. Pathological results of all cases were reported as testicular epidermoid cyst. The mean testicular mass volume was $28 \mathrm{~mm}^{3}$ (range, 13 to $51 \mathrm{~mm}^{3}$ ). Mean follow-up period was 66.9 months (range, 12 to 216 months). No recurrent cases were detected during the follow-up period (Table 1).

\section{Discussion}

Testicular epidermoid cysts are rare benign lesions of the testis [7]. The lesions are more common in non-white men and their 2nd and 3rd decade of life [8]

Table 1. Evaluation of descriptive characteristics in patients with epidermoid cyst of the testis was managed by inguinal orchiectomy.

\begin{tabular}{cc}
\hline Variable & Mean (Min - Max) \\
\hline Age (years) & $29.7(20-53)$ \\
Size of Cyst $\left(\mathrm{mm}^{3}\right)$ & $28(13-51)$ \\
Follow-Up (month) & $66.9(12-216)$ \\
Recurrence (n) & 0 \\
\hline
\end{tabular}


[9]. They are often misinterpreted as germ cell tumors. Epidermoid cyst of the testis accounts for about $1 \%-2 \%$ of all testicular masses [10]. Therefore, there are no studies in the literature with a high number of patients. The majority of studies in the literature are in the form of case reports and there are a limited number of studies with long-term follow-up results.

The main theory of embryological development is monodermal development of a teratoma. Another theory suggests that it originates from metaplasia of squamous epithelium [11]. Its etiological origin has not been elucidated yet. Epidermoid cysts are benign lesions with no risk of malignant transformation, but they can reach very large diameters, causing damage to, or displacement of adjacent organs [12]. In our cases, testicular tissue was compressed by the mass lesions. In addition to these, no metastases were detected with metastasis screening for suspected testicular tumors and no recurrence was observed during the approximately 5-year follow-up period.

Testicular epidermoid cysts can be seen in childhood as well as in adults. Wu et al. [13] reported a patient with testicular epidermoid cyst who was 3 months old at diagnosis. In adults, cases are more commonly diagnosed in the 2 nd and 3rd decades. In our cohort, the results were consistent with literature.

Most patients are asymptomatic and scrotal pain, scrotal swelling, painless mass or a combination of these symptoms may be found in the medical history [14]. Testicular epidermoid cysts cannot be clinically distinguished from other testicular tumors. In contrast to the literature, there were no asymptomatic patients in our study. We think that patients should be routinely questioned for symptoms other than scrotal pain. It should not be forgotten that scrotal swelling affects social life, especially in cases of large testicular epidermoid cysts.

The size of the testicular mass affects the testicular symptoms. Paffenholz et al. [15] found that a cutoff of $28 \mathrm{~mm}^{3}$ mass volume most accurately differentiated between benign and malignant disease. In our cohort, the maximum lesion size was $51 \mathrm{~mm}^{3}$ and four patients had lesion volumes of over $28 \mathrm{~mm}^{3}$. Our results support this study and suggest that small testicular masses without elevated tumor markers are benign.

In general, the lesions are round or oval and are heterogeneous without vascularity or blood flow on ultrasonography of the scrotum (Figure 1). Different descriptions can be made based on echogenicity and localisation of calcifications [16]. Radiological findings may demonstrate an "onion skin" or appearance and some lesions may show a "target sign" appearance. On MRI, testicular epidermal cysts are described as high-intensity, well-defined solid masses surrounded by a low-signal capsule on T2-weighted imaging [17]. Langer et al. [18] and Kondo et al. [19] showed that on $\mathrm{T}_{1}$-weighted $\mathrm{MR}$ images, some lesionshad low signal-based, center with spotty high signal ("target" sign) and on $\mathrm{T}_{2}$-weighted MRI, some lesions had a laminated appearance, with alternating low and high signal intensity areas ("onion skin" sign). Although MRI is not routinely performed in our practice, we found the same findings in one patient. In addition, 


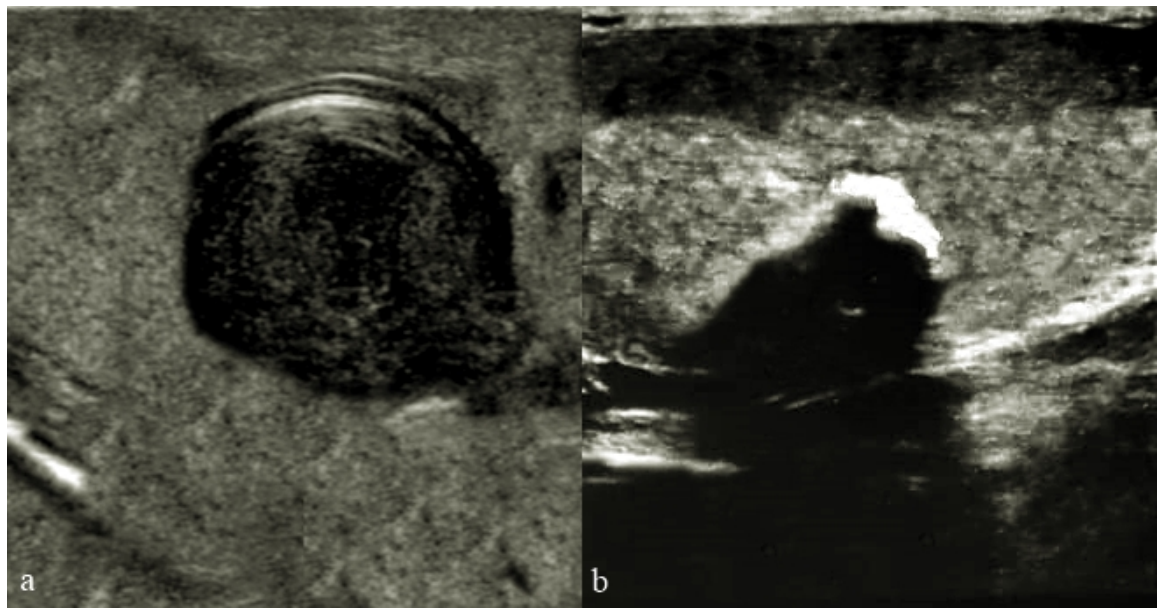

Figure 1. Onion ring or target sign (a) and hyperechogenic appearance (b) in ultrasonographic findings of the testicular epidermoid cyst.

although epidermoid cysts have typical findings, it is not always possible to distinguish them from other scrotal lesions.

Testicular germ cell tumors, testicular teratomas, dermoid cysts, tuberculosis and focal testicular hemorrhage should be considered in radiological differential diagnosis. Testicular germ cell tumors tend to show vascularity, testicular teratomas have a similar appearance and are distinguished by histopathological examination and tunica albuginea cysts tend to be completely anechoic [20] [21] [22]. Although very rare, Khalafalla, et al. [23] reported a scrotal glomus tumor very similar to epidermoid cysts, which presented with a painful right scrotal swelling.

In histopathological microscopic examination, epidermoid cyst of the testis is lined by squamous epithelium with a granular layer, fibrous wall and lamellar keratinization in the lumen (Figure 2). Testicular germ cell tumors, testicular teratomas, dermoid cysts, IGCNU (intratubular germ cell neoplasia) in seminiferous tubules, tuberculosis and hemorrhage were considered in the histopathological differential diagnosis. The whole testicular parenchyma was examined and there was no component of germ cell tumor, teratoma or IGCNU. Seminiferous tubules with varying degrees of maturation containing spermatocyte and spermatogonia and sertoli cells were observed in the testicular parenchyma. In addition, the cyst wall contained no adnexal structures, unlike dermoid cysts. There were neither tuberculosis granulomas nor bleeding in the testicular tissue.

\section{Conclusions}

Testicular epidermoid cysts are rare lesions and there is not enough information in the literature recurrence and follow-up. There are limited preoperative findings that help distinguish epidermoid cysts from testicular tumors. In recent years, testicular sparing surgery has been more commonly recommended and performed, especially in patients with lesions that are negative for tumor markers and that have radiological findings typical of epidermoid cysts. Annual 


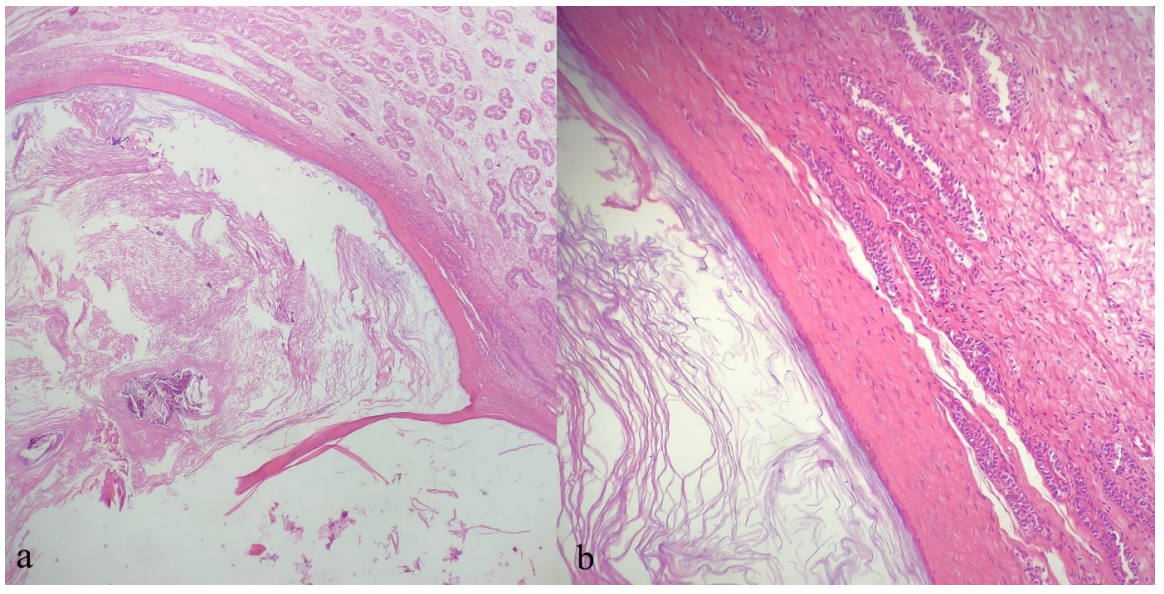

Figure 2. H\&E $\times 100$ (a) and $\times 200$ (b) cystic tissue with fibrous wall, keratinous debri in the lumen and seminiferous tubules around the cyst.

follow-up is not required since there is no risk of recurrence.

The limitations of our study include its retrospective nature and the small number of patients with testicular epidermoid cyst. However, it should be noted that the incidence of the disease is extremely low.

\section{Conflicts of Interest}

The authors certify that there is no conflict of interest with any financial organization regarding the material discussed in the manuscript.

\section{References}

[1] Yamamoto, K., Takada, T., Momohara, C., Komori, K., Honda, M. and Fujioka, H. (2003) Epidermoid Cyst of the Testis Difficult to Make a Preoperative Diagnosis on the Echoic Examination: A Case Report. Hinyokika kiyo. Acta Urologica Japonica, 49, 213-215.

[2] Docal, I., Crespo, C., Pardo, A., Prieto, A., Alonso, P. and Calzada, J. (2001) Epidermoid Cyst of the Testis: A Case Report. Pediatric Radiology, 31, 365-367. https://doi.org/10.1007/s002470100443

[3] Dockerty, M.B. and Priestley, J.T. (1942) Dermoid Cysts of the Testis. Journal of Urology, 48, 392-397. https://doi.org/10.1016/S0022-5347(17)70726-4

[4] Marchal Escalona, C., Caballero Alcantara, J., Padilla Leon, M., Rodrigo Fernandez, I. and Gonzalez de la Granda, F. (1999) Epidermoid Cyst of the Testis. A Case of Difficult Preoperative Diagnosis. Actas Urológicas Españolas, 23, 176-178.

[5] Manning, M.A. and Woodward, P.J. (2010) Testicular Epidermoid Cysts: Sonographic Features with Clinicopathologic Correlation. Journal of Ultrasound in Medicine, 29, 831-837. https://doi.org/10.7863/jum.2010.29.5.831

[6] Fuse, H., Takahara, M., Ishii, H., Sumiya, H. and Shimazaki, J. (1990) Measurement of Testicular Volume by Ultrasonography. International Journal of Andrology, 13, 267-272. https://doi.org/10.1111/j.1365-2605.1990.tb01031.x

[7] Chen, S.T., Chiou, H.J., Pan, C.C., Shen, S.H., Chou, Y.H., Tiu, C.M., Wang, H.K., Lai, Y.C., Lin, Y.H., Wang, J. and Chang, C.Y. (2016) Epidermoid Cyst of the Testis: An Atypical Sonographic Appearance. Journal of Clinical Ultrasound, 44, 448-451. 
https://doi.org/10.1002/jcu.22355

[8] Malek, R.S., Rosen, J.S. and Farrow, G.M. (1986) Epidermoid Cyst of the Testis: A Critical Analysis. British Journal of Urology, 58, 55-59.

https://doi.org/10.1111/j.1464-410X.1986.tb05428.x

[9] Dieckmann, K.P. and Loy, V. (1994) Epidermoid Cyst of the Testis: A Review of Clinical and Histogenetic Considerations. British Journal of Urology, 73, 436-441. Https://doi.org/10.1111/j.1464-410X.1994.tb07611.x

[10] Cho, J.H., Chang, J.C., Park, B.H., Lee, J.G. and Son, C.H. (2002) Sonographic and MR Imaging Findings of Testicular Epidermoid Cysts. AJR American Journal of Roentgenology, 178, 743-748. https://doi.org/10.2214/ajr.178.3.1780743

[11] Behzatoğlu, K., Bahadır, B., Toktaş, G., Sarı, C., Ünlü, Y. and Topçuoğlu, C. (2001) Testiste epidermoid kist (Olgu sunumu). Türk Patoloji Dergisi, 17, 87-89.

[12] Fakhir, B., Mamouni, N., Bouramdane, N., Bouchikhi, C., Bouguern, H., Chaara, H., Melhouf, M. and Banani, A. (2009) A Rare Case of a Giant Pelvic Retroperitoneal Epidermoid Cyst. Libyan Journal of Medicine, 4, 61. https://doi.org/10.3402/ljm.v4i2.4811

[13] Wu, D., Shen, N., Lin, X. and Chen, X. (2018) Prepubertal Testicular Tumors in China: A 10-Year Experience with 67 Cases. Pediatric Surgery International, 34, 1339-1343. https://doi.org/10.1007/s00383-018-4366-6

[14] Loya, A.G., Said, J.W. and Grant, E.G. (2004) Epidermoid Cyst of the Testis: Radiologic-Pathologic Correlation. RadioGraphics, 24, S243-S246.

https://doi.org/10.1148/rg.24si035223

[15] Paffenholz, P., Held, L., Loosen, S.H., Pfister, D. and Heidenreich, A. (2018) Testis Sparing Surgery for Benign Testicular Masses: Diagnostics and Therapeutic Approaches. Journal of Urology, 200, 353-360. https://doi.org/10.1016/j.juro.2018.03.007

[16] Manning, M.A. and Woodward, P.J. (2010) Testicular Epidermoid Cysts: Sonographic Features with Clinicopathologic Correlation. Journal of Ultrasound in Medicine, 29, 831-837. https://doi.org/10.7863/jum.2010.29.5.831

[17] Su, J., Jiang, T., Liu, X. and Zhai, R. (2014) Diagnosis and Differential Diagnosis of Testicular Epidermoid Cyst with MRI. National Medical Journal of China, 94, 2139-2142.

[18] Langer, J.E., Ramchandani, P., Siegelman, E.S. and Banner, M.P. (1999) Epidermoid Cysts of the Testicle: Sonographic and MR Imaging Features. AJR American Journal of Roentgenology, 173, 1295-1299. https://doi.org/10.2214/ajr.173.5.10541108

[19] Kondo, T., Kawahara, T., Matsumoto, T., Yamamoto, Y., Tsutsui, M., Ohtani, M., Ohtaka, M., Kumano, Y., Maeda, Y., Mochizuki, T., Mori, K., Asai, T., Kuroda, S., Takeshima, T., Hattori, Y., Teranishi, J., Miyoshi, Y., Yumura, Y., Yao, M., Inayama, Y. and Uemura, H. (2016) Epidermal Cyst in the Scrotum Successfully Treated while Preserving the Testis: A Case Report. Case Reports in Oncology, 9, 235-240. https://doi.org/10.1159/000445826

[20] Maizlin, Z.V., Belenky, A., Baniel, J., Gottlieb, P., Sandbank, J. and Strauss, S. (2005) Epidermoid Cyst and Teratoma of the Testis: Sonographic and Histologic Similarities. Journal of Ultrasound in Medicine, 24, 1403-1409.

[21] Kim, W., Rosen, M.A., Langer, J.E., Banner, M.P., Siegelman, E.S. and Ramchandani, P. (2007) US-MR Imaging Correlation in Pathologic Conditions of the Scrotum. RadioGraphics, 27, 1239-1253. https://doi.org/10.1148/rg.275065172

[22] Dogra, V.S., Gottlieb, R.H., Rubens, D.J. and Liao, L. (2001) Benign Intratesticular 
Cystic Lesions: US Features. RadioGraphics, 21, S273-S281.

https://doi.org/10.1148/radiographics.21.suppl_1.g01oc15s273

[23] Khalafalla, K., Al-Ansari, A., Omran, A., Farghaly, H. and Alobaidy, A. (2017) Glomus Tumor of the Scrotum: A Case Report and Mini-Review. Current Urology, 10, 213-216. https://doi.org/10.1159/000447183 